American Journal of

Supply Chain Management

(AJSCM)

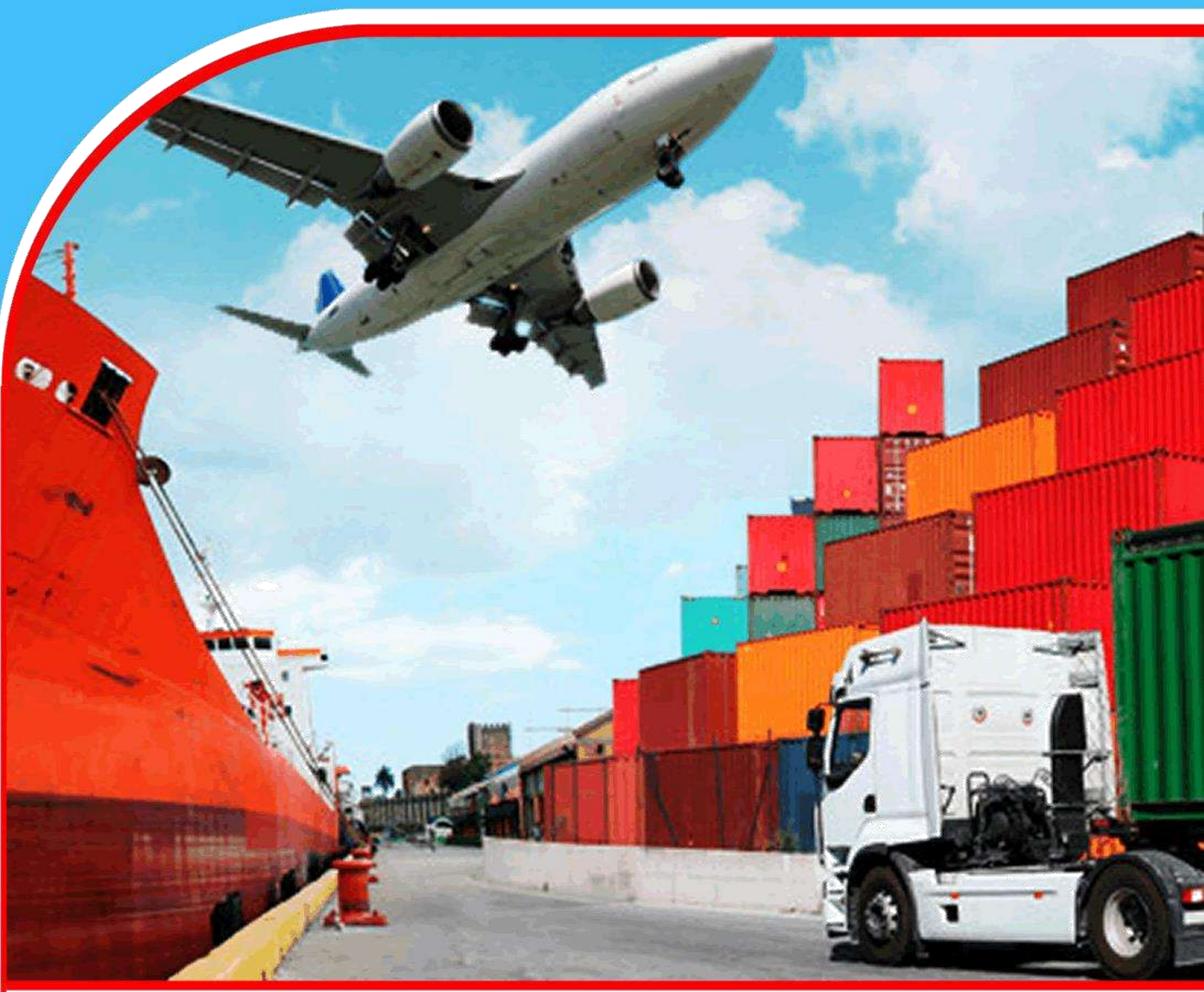

REVIEW OF COFFEE VALUE CHAIN IN ETHIOPIA ON THE COURSE CROP VALUE CHAIN MANAGEMENT 


\title{
REVIEW OF COFFEE VALUE CHAIN IN ETHIOPIA ON THE COURSE CROP VALUE CHAIN MANAGEMENT
}

\author{
$1 *$ Temesgen Kabeta \\ ${ }^{1 *}$ Student, College of Agriculture and Veterinary Medicine, Ethiopia \\ *Corresponding Author's Email: tamekabeta2016@gmail.com
}

\begin{abstract}
Purpose: This purpose of the study was to review of coffee value chain in Ethiopia on the course crop value chain management

Unique contribution to theory, practice and policy: The value chain actors must play a critical role to increases the profit plow back in the Ethiopian coffee sector and then will significantly improve living standards of the poor who are at the source of the chain.
\end{abstract}

Key words: value Chain, coffee sector, production 


\subsection{INTRODUCTION}

\subsection{Background}

Agriculture continues to be the main job creators of Africa's increasingly young population of 1.1 billion inhabitants. The rural population continues to increase rapidly, exacerbating the problems of poverty. Africa's 25 coffee-producing countries are home to over 716 million people, and in some of those countries coffee is an important commodity in terms of both export earnings and generating income for smallholder farmers. According to (document ICC-114-5, 2015) and seeks to analyze the dynamics of the coffee sector in Africa and the huge challenges to its sustainability.

According to (Tefera \& Tefera, 2013) Smallholder farmers produce 95 percent of Ethiopia's coffee. It is produced under several types of production systems, including forest, semi-forest, garden, and plantation coffee (Tulu, 2008). Forest coffee is grown in the wild under natural forest cover and is gathered by farmers from trees with minor tree maintenance. Semi-forest coffee is also grown in forest conditions, but there is some limited maintenance by farmers, mostly annual weeding. This type of coffee has clearly delineated boundaries of ownership, although the trees usually are located away from agricultural plots.

Garden coffee is defined as coffee from trees planted by farmers in the vicinity of their residences. It is often intercropped with other crops or trees. Plantation coffee is grown on large commercial farms, private as well as state farms. Modern production practices - such as irrigation, modern input use, mulching, stumping, and pruning - are often applied in this case. While reliable recent statistics are lacking, it is estimated that these different production systems make up about 10, 35, 50, and 5 per-cent, respectively, of total coffee production in the country (Kufa, 2012).

According to (ICC-114-5, 2015) report, a sustainable coffee economy is based on the well-being of the various actors in the chain, particularly the producers who are the weakest link in this relationship. More precisely, a sustainable coffee farmer will meet long term environmental and social goals while being able to compete effectively with other market participants and achieve prices that cover his/her production costs and allow him to earn an acceptable profit margin. The question that needs to be addressed is whether coffee growing is sustainable in Africa

Coffea originated in the Kaffa region of Ethiopia where it grows naturally. It became an item of trade with Yemen in the fifteenth century and by 1700 the ports of Aden and Mocha were sources of what became Arabica coffee seeds. French missionaries planted some in Bourbon (now Reunion) Island in 1708, and by 1817 about 3,000 tons were being produced annually.

A value chain consists of value-adding activities involved in production, processing, delivery (transportation and marketing) and retailing of a product. In more recent times, the postconsumption activities in form of waste management through, say, recycling, waste reduction and environment values are being integrated in value chain analysis. In economic terms, the "value" in value chain constitutes the sum total of payments made by industries to workers, profits, dividends, capital gains and indirect business taxes paid to state and local governments. Valueadded, then, is the money that remains in an economy that may be used for household spending, saving, or capital investment.

This important commodity has been given greater attention by the country, and it is the first cash crop with which the Ethiopia Commodity Exchange (ECX) commenced trading operations in April 
2008 so as to improve the coffee markets in Ethiopia. According to ECX (2011), agricultural markets in Ethiopia before 2008 had been characterized by high costs and high risks of transacting, with only one third of output reaching the market, and besides, small-scale farmers, who produce 95 percent of Ethiopia's output, came to market with little information and are at the mercy of merchants in the nearest market they know, and they are unable to negotiate better prices or reduce their market risk.

The study by Aklilu and Ludi (2010) indicated that even though the government deals with coffee marketing, there are still a lot of problems faced by the farmers. For instance, farmers reported government's insufficient regulation of the price of coffee where collectors and suppliers set their own price which is usually below the market price as announced by the government.

The specific objectives of this seminar is to review coffee production, coffee value chain as well as challenges and opportunity of coffee value chain in Ethiopia

\subsection{COFFEE VALUE ADDITION AND VALUE CHAIN IN ETHIOPIA}

\subsection{Coffee Production in Ethiopia}

Ethiopian economy is basically dependant on agriculture which contributes about $40 \%$ of the GDP, and $80 \%$ of exports (John and Nebil, 2010). Currently, coffee is the major agricultural export crop, providing $65 \%$ of Ethiopia's foreign exchange earnings. In the country, where about large amount of the population is under poverty, coffee cultivation plays a vital role both in the cultural and socio-economic conditions of the nation. According to World Bank report, about $25 \%$ of the Ethiopian population depends directly or indirectly, on coffee production, processing and marketing (World Bank, 2009).

Ethiopia is known with having a suitable environment for growing coffee with a combination of suitable altitude, temperature, rainfall, soil type, and $\mathrm{pH}$. Ethiopia is origin for Coffeaarabica. The country possesses a diverse genetic base for this Arabica coffee with considerable heterogeneity. Ethiopia produces a range of distinctive Arabica coffees and has considerable potential to sell a large number of specialty coffees (Nure, 2008). Little of the lower-value Robusta coffee is produced in Ethiopia, being better suited for production in lower altitude equatorial climates. Coffee production in Ethiopia is almost exclusively situated in the two regions of Oromia and the Southern Nations, Nationalities, and People Regions (SNNPR) in the south and west of the country.

According to (Tefera and Tefera, 2013) 95 percent of Ethiopia's coffee produced Smallholder farmers. It is produced under several types of production systems, including forest, semi-forest, garden, and plantation coffee (Tulu, 2008). Forest coffee is grown in the wild under natural forest cover and is gathered by farmers from trees with minor tree maintenance. Semi-forest coffee is also grown in forest conditions, but there is some limited maintenance by farmers, mostly annual weeding. This type of coffee has clearly delineated boundaries of ownership, although the trees usually are located away from agricultural plots. Garden coffee is defined as coffee from trees planted by farmers in the vicinity of their residences. It is often intercropped with other crops or trees. Plantation coffee is grown on large commercial farms, private as well as state farms. Modern production practices - such as irrigation, modern input use, mulching, stumping, and pruning - are often applied in this case. While reliable recent statistics are lacking, it is estimated that these different production systems make up about 10,35, 50, and 5 percent, respectively, of total coffee production in the country (Kufa, 2012). 
A markets emerging, many coffee-dependent developing countries such as Ethiopia are struggling with production and marketing of their coffee. In the early 2000s, a historic world market price slump hit millions of coffee farmers hard, especially smallholder producers in Africa and Latin America (Ponte, 2002) as cited in IAAE,2012.Therefore, the Ethiopian farmers at the time were take a measure to resist the market price fall by reducing coffee plantation replacing chate plantation in place of coffee. Settled agriculture began in Ethiopia some 2000 years ago, and as long as anyone can remember Coffee Arabica has been grown in the wild forests of the southwestern massive highlands. Export began to Yemen, and was from there introduced to Indonesia, India, The Netherlands, Colombia and Brazil. Coffee in Ethiopia is not only an important export good but it is a part of the culture; about $50 \%$ of the produced coffee is consumed domestically and there is even a cultural ceremony connected to it. Total production of washed and unwashed coffee is increasing (ToraBäckman, 2009).

According to (Alemseged \& Getaneh, 2013) Ethiopia is the world's fifth largest coffee producer and Africa's top producer, with estimated coffee production of more than 450,000 tons and marketable supply of 334,000 metric tons in farm year 2012/13. Half of the coffee produced consumed locally and the country leads the African Continent in domestic consumption. It has been used income generation for that about 20 percent of the populations, directly or indirectly, depend for a living on coffee production and trading.

According to (Anwar, 2010) coffee is the most important crop in the national economy of Ethiopia and the leading export commodity. Ethiopia is well known not only for being the home of Arabica coffee, but also for it is very fine quality coffee acclaimed for its aroma and flavor characteristics. Another promising potential of Ethiopian coffee is its diversity of variety and quality. According to Luxner"s report (2001) quoting Ethiopian most diversified coffee types. The major five of these are the following.

Harar. It is produced in the eastern highlands, at altitudes of 1,510 to 2,120 meters asl.

Wollega (Nekemte). It is known for its fruity taste has medium-to-bold sized beans, agreenishbrownish color.

Limu. It is produced at altitude 1,400 to 2,020 meters above sea level. The beans aregreenishbluish in color and mostly round in shape, and have a medium-sized.

Sidamo. It is produced in southern Ethiopia, at altitudes of between 1,400 and 2,200 meters above sea level.

Yirgacheffee. It is a highland grown coffee, which is grown at altitudes of between 1,770 and 2,000 meters above sea level.

Ethiopia encompasses a potential opportunity to increase coffee production. It is endowed with suitable elevation, temperature, and soil fertility, indigenous quality planting materials, and sufficient rainfall in coffee growing belts of the country. Coffee is a shade-loving tree. Forest coffee yield is low as considered to garden and semi-forest coffee because resource ownerity belongs to communal and poor management. As explained Ethiopian coffee annual report 2013, average per hectare yield remains very low at $0.72 \mathrm{MT}$ per hectare.

As see from the below table, the general trend of annual coffee production in Ethiopia is increasing. A declining growth was observed in 2001 (which was negative 26.4 percent) and in 2006 (negative 9.5 percent). The highest growth in coffee production in the new millennium was in 2002 (35.7 
percent), which is a very good year of production in terms of rainfall availability. The next highest was in 2005 (29.1\%) followed by 21.5 percent in 2007, see table 2.2. for the trends and comparison.

Table 2.1 Comparison of Coffee Production Supply of some selected countries

\begin{tabular}{lccc}
\hline \multicolumn{1}{c}{ Country } & Production & & \\
& Percentage share & Rank \\
\hline Brazil & (in 1000 Bags)* & & \\
Viet Nam & 37,600 & 30.73 & 1 \\
Colombia & 18,062 & 14.76 & 2 \\
Indonesia & 12,400 & 10.13 & 3 \\
Ethiopia & 6,650 & 5.43 & 4 \\
India & 6,000 & 4.90 & 5 \\
Mexico & 4,650 & 3.80 & 6 \\
Guatemala & 4,500 & 3.68 & 7 \\
Honduras & 4,100 & 3.35 & 8 \\
Peru & 3,600 & 2.94 & 9 \\
Other countries & 3,190 & 2.61 & 10 \\
Total & 21,607 & 17.67 & \\
\hline
\end{tabular}

SOURCE: USDA as cited by index mundi, 2008 estimate *note: One bagis equal to $60 \mathrm{~kg}$.

Figure 2.1.The percent share of Ethiopia and Africa in world 


\section{$\%$ share of Africa \& Ethiopia in world production Coffee years $1980 / 81$ to $2011 / 12$}

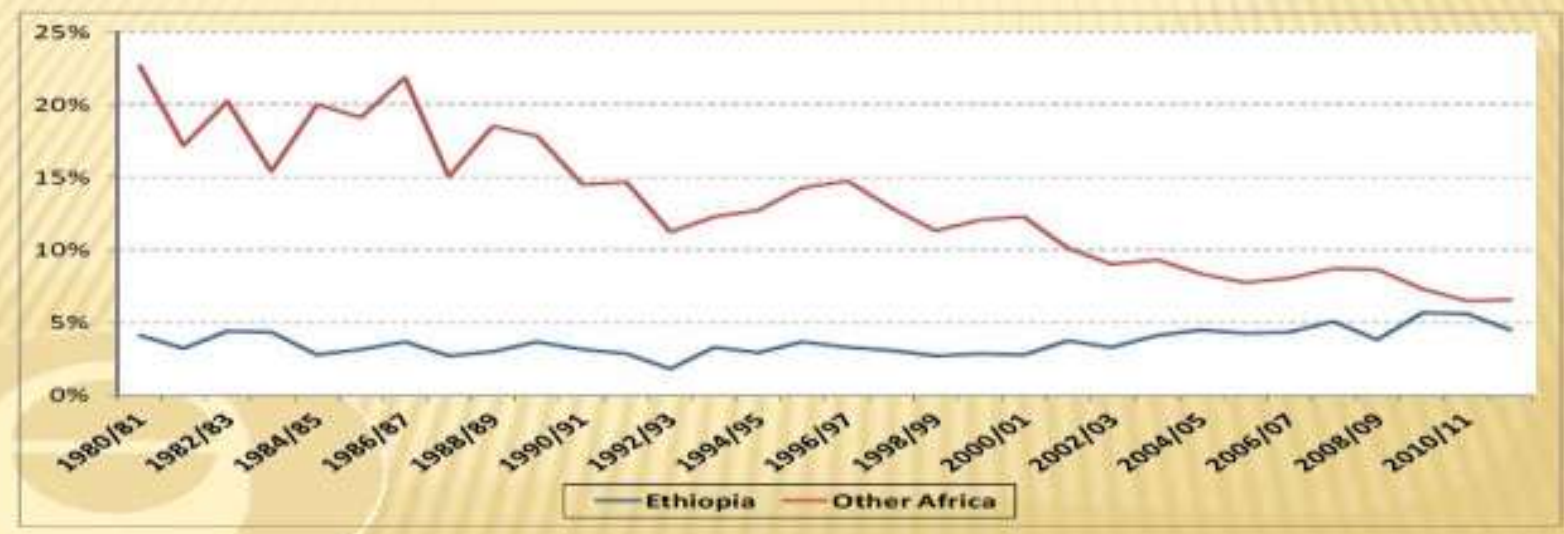

And also when we compare the level of Ethiopian coffee export with other African countries Figure 2.2 Percent share of Ethiopian coffee with Africancountries

\begin{tabular}{|c|c|c|c|c|}
\hline \multicolumn{5}{|c|}{ (Averages in thousand bags) } \\
\hline & $1980-89$ & $1990-99$ & $2000-09$ & $2010-12$ \\
\hline TOTAL AFRICA & 16664 & 14636 & 11546 & 10676 \\
\hline Uganda & 2448 & 3002 & 2769 & 2939 \\
\hline Ethiopia & 1370 & 1481 & 2368 & 2927 \\
\hline Côte d'Ivoire & 3806 & 3823 & 2393 & 1311 \\
\hline Tanzania & 851 & 783 & 766 & 709 \\
\hline Kenya & 1631 & 1363 & 747 & 661 \\
\hline Cameroon & 1643 & 1050 & 741 & 515 \\
\hline Guinea & 59 & 123 & 344 & 373 \\
\hline Burundi & 508 & 483 & 321 & 304 \\
\hline Rwanda & 594 & 336 & 303 & 254 \\
\hline Others & 3755 & 2193 & 793 & 683 \\
\hline
\end{tabular}

\subsection{Coffee value chain In Ethiopia}

According to (USAID, 2010) the producers under this stage in the coffee value chain of Ethiopia include small-scale farmers, private owned farmers and state firms. The major portion inters of volume of products mobilized, value adding functions, market share and capital owned in coffee value chain of the country is under the hands of producers especially the large-scale private coffee plantations and state farms of coffee plantations. After the coffee is grown and matured, the 
following value adding activities in the value chain performed by those producers are collecting coffee chary and transporting to processing areas (USAID, 2010).

Packing dry coffee loading, transporting, and unloading to the warehouses transported to the final market through ECX is also value addition. While some of the large scale, private coffee producers sell their products the exporters either in Addis Ababa or to international importers.

According to (Minten etal, 2015) there has been increasing adoption of improved production, harvest, and post-harvest practices with positive impacts on coffee productivity and incomes. Upstream marketing has improved, and there have been large investments in processing capacity, shown by the extended coverage of wet mills. These changes seem to have been driven by greater availability of extension agents, market reform, and high international prices. However, despite these changes, yield growth has been small. The prevalence of coffee diseases, weather shocks, lack of improved seedlings, and saving constraints has impeded uptake of improved practices with consequent repercussions on farmers' productivity and income.

\subsubsection{Coffee market Channels}

Ethiopian coffee value chain is composed of a large number of actors. It includes coffee farmers, collectors, different buyers, processors, primary cooperatives, cooperative unions, exporters and various government institutions (Gemechu and Struthers, 2007). Ethiopian coffee is sold both at local and international market. The latter mainly operates through the newly established commodity exchange market and specialty market channels of coffee cooperative unions. Before 2001, all Ethiopian coffee should pass through Commodity Exchange Market. Since 2001, however, cooperatives have been granted permission to by-pass coffee auction opening the way for direct export sales.

The local development agents advise, inspect and support farmers during before harvests, during harvests, and after harvest so as to maintain its quality. Farmers, local private traders, farmers and cooperatives assemble coffee produced in different Zones. The coffee assembled is transported to local processors if it is wet- processed and to the central market in Addis Ababa and Dire Dawa if it is sun-dried for the Ethiopian current regulation requires all coffee to be inspected at the center in Addis Ababa and Dire Dawa. After processing is completed, wet-processed coffee too, is transported to central markets for further inspection and auction sale. The Coffee Standard and Quality Inspection and Auction Centers monitor the production and exportation of all coffee through the system. In the supply chain the NCBE had the responsibility of inspecting, organizing and coordinating the classification, grading and auction sale of the coffee supplied to central markets in Addis Ababa and Dire Dawa with its own operational rules, regulations, and modalities (Ibid).

\section{Figure 2.3 Coffee Supply Chain in Ethiopia}

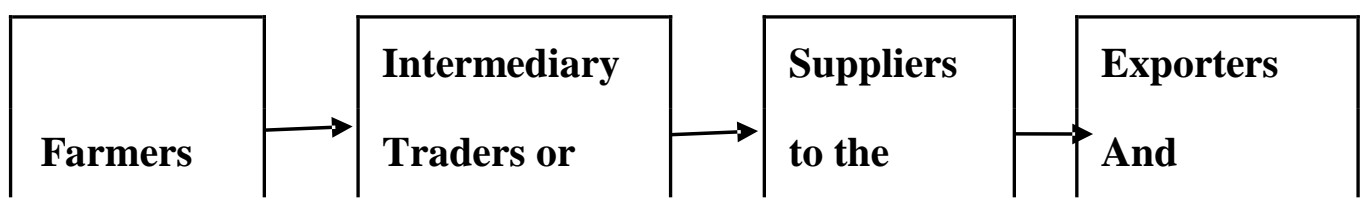




\begin{tabular}{|l|l|l|l|l|l|l|l|} 
Processors \\
\end{tabular} \mid

Source: Böhnert, E. \& N. Dieter, 2011

Table 2.2 Functions and actors along the coffee value chain in Ethiopia

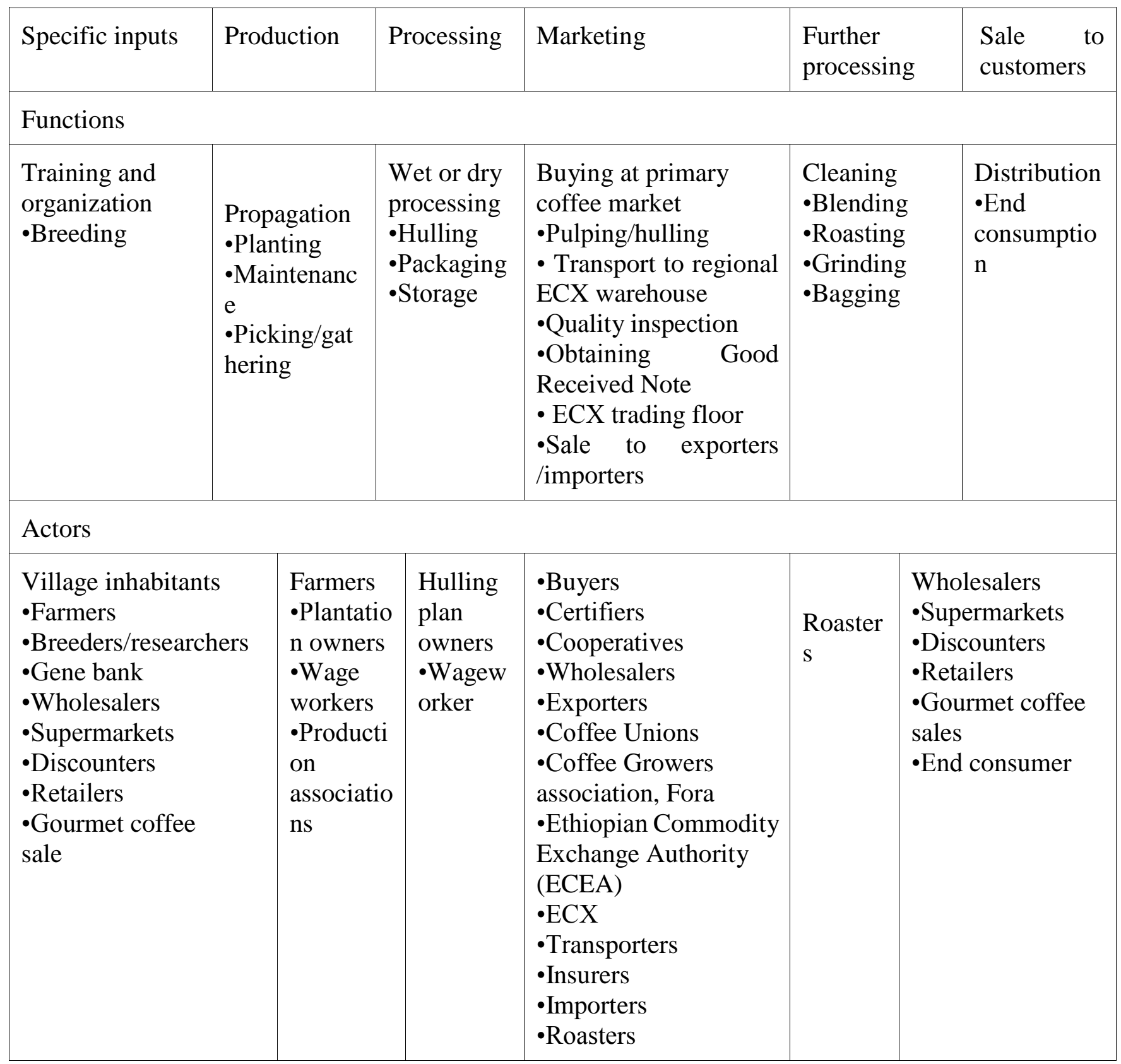


Source: Authors, based on Böhnert, E. \& N. Dieter, 2006

\subsubsection{Coffee Collectors}

The most important participants in coffee value chain and they directly bought the coffee with its pulp (Jenfel coffee) and/or without pulp and sold it to suppliers or private traders for further processing activities and preparation for marketing. Coffee collectors (sebsabies') play an essential role of bringing coffee from very remote areas to the market by adding value augmenting the volume of coffee (USAID.2010).

According to (Dessalegn and Solomon, 2014) marketing costs, margin and benefit analysis imply that coffee collectors incurred the lowest cost which was 7.97 birr per $17 \mathrm{~kg}$. Coffee producers bear the highest cost followed by wholesalers which was 104.98 birr and 48.67 birr per $17 \mathrm{~kg}$ respectively. The average coffee wholesaler retained significant annual total net benefit than producers and coffee collectors. The estimated annual net benefits of a typical coffee producer, collector and wholesaler were birr 3879.88, 1708.28, and 390257.06, respectively. This implies that coffee trading is highly profitable at the wholesale level. The producers' share as a percentage of wholesale prices is low as compared to farmers in other regions of the country.

\subsubsection{Traders (Suppliers)}

According to (Alemayehu Asfaw, 2014) Suppliers in coffee value chain of Ethiopia are those who buy coffee from collectors (both legal and illegal collectors) and sell it to either to exporters in Addis Ababa auction market or international importers. Suppliers acquire red coffee cherries from collectors or producers and process their coffee before bringing it to auction. They have hulling, washing and other sophisticated machines for processing purposes. There are wet and dry processing types performed by the processors. In the case of wet processing, after the harvested coffee cherries immediately pulped, fermented in tanks and then finally washed in clean water to remove the mucilage. It then dried in the sun on raised tables and sorted at proper moisture content. After drying to proper moisture content, the outer layer of the cherries removed by hulling and the green bean obtained is ready for marketing. The value addition in this level is totally related processing activities.

\subsubsection{Primary Cooperatives and Unions}

The primary cooperatives in Ethiopia are important participants in the coffee value chain of the country. They produce and harvest the coffee and some of them even perform some processing activities like washing pulping, sorting and finally sell it to their respective unions. The unions process the coffee or further processing. Finally further processed were packed, transported to their warehouse and make ready for export market. Here the unions have different alternatives to sell their products. They can sell directly to the international importer or to the domestic exporter through ECX. The coffee unions contact to ECX for grading systems and to follow the rules and regulation of the government of Ethiopia (Alemayehu Asfaw, 2014).

\subsubsection{Exporters}

After the all the coffee production and processing activities are finished, it exported to the international market by exporters. Exporters found in Addis Ababa central market who received coffee from private producers, private traders and cooperative unions to sell it to the international market. These exporters bought the coffee from the central auction market through ECX. These coffee exporters do not get any coffee from the state producers, because state farm producers 
export coffee to foreign market by themselves. They play a significant role by searching foreign market through the linkage they have with the importers outside the country. They add a place utility to the commodity coffee. Here, the unions, the private traders and the state owned producers could also act as exporters of coffee, since they can directly sell it to the foreign importers (MOT, 2012).

\subsubsection{Importers}

Imports are those actors outside the country who buy coffee from different exporters in the country Ethiopia. The Ethiopian coffee importing countries are first German coffee importer, Japan, the Netherlands, and America. These foreign importers after adding some value to the coffee they received, they directly sell to wholesalers and then to supermarkets (MOT, 2012).

\subsubsection{Domestic Wholesalers and Retailers}

The other important actors in coffee value chain in Ethiopia are wholesalers who directly buy coffee from the household farmer's or small-scale farmers. The small-scale farmers, who harvest, dry and hull the coffee and transport to market in Ethiopia. By doing so it the small-scale farmers play a significant role in adding a value on coffee. Here the function of hulling will go to retailers in that they add more value on the coffee and finally sell to consumers after hulling it (MOT, 2012).

\subsubsection{Consumers}

Consumers are the ultimate users of the commodity coffee. In the coffee value chain in Ethiopia, there are varieties of consumers of coffee. These are domestic consumers and foreign consumers. The consumers present in domestic country consume directly from small-scale farmers and coffee collectors retailers throughout the country (MOT, 2012).

\subsubsection{Service Providers at Each Value Chain}

The service provider in coffee value chain actors in the country are like Ethiopian commodity exchange main and its branch, input supplying government organizations, Woreda level administration bodies, development agents, transporters, credit and other financial service providers (commercial bank of Ethiopia, saving and credit association and other non-governmental organizations (MOT,2012).

According to (Berhanu etal, 2013) In Ethiopian coffee value chain, the participants are numerous which include smallholder coffee farmers or state farms, primary collectors, suppliers, processors, service cooperatives, unions, exporters and various governmental institutions. Practically, collectors sell to suppliers, suppliersdeliver to the auction (they are not permitted to export), and the auction tender to the exporters. Normally, all Ethiopian coffee should pass through auction center. According to the rule of Ethiopian Commodity Exchange (ECX), a firm should not participate on two or more stages of the value chain. These generic functions are mapped in seven groups as input supply, production, primary marketing, primary processing, trading, green coffee exporting and secondary processing.

Figure 2.4 Value chain map of Ethiopian coffee 


\begin{tabular}{lllllll}
\hline Peedling & Production & Primary & Primary \\
Seed & Planting & Collection & De-husking & Transporting & Cleaning & Storage \\
Compost & Weeding & Transporting & Fermenting & Storing & Roasting & Sorting \\
Poly Bag & Cultivation & Packing & Washing & Grading & Grinding & Packing \\
Labour & Pruning & Selling & Drying & Packing & Copping & Regarding \\
Farm Tool & Tamping & & Cleaning & Selling & Packing & Shipping \\
& Picking & & Cupping & & & \\
& Harvesting & & Storing & & & \\
& Collecting & Packing & & & \\
\hline
\end{tabular}

\section{SOURCE: Berhanu, etal, 2013}

According to this author Marketing of coffee starts on the farms by producers/farmers. Farmers are the main actors in the coffee value chain. They are involved in transporting of their product to the purchaser's site or give information to collectors. The starting price for the red cherries is first announced by the washing stations owned by cooperatives or private individuals. Local collectors buy red cherries and send immediately to washing stations. Since cooperatives are the owners of washing plants/station, they determine the starting price for a kilogram of fresh red cherries and are followed by private washing stations. During the 2009/10 coffee season, they set a price that ranged between 8 and $12 \mathrm{Birr} / \mathrm{kg}$, to which private processors added up to $10 \mathrm{Birr} / \mathrm{kg}$. The income is mostly spent on food items for household consumption. They sell on average 3 to $10 \mathrm{~kg}$ of coffee daily to local collectors in the village. The value addition and operational benefits in each stage of the value chain are determined to identify possible intervention areas. This analysis is conducted only by considering dry coffee export value chain from the area of coffee origin Keffa and Jimma. According to study conducted by (Berhanu etal, 2013) the sum of value addition made throughout the chain is:

$$
\Sigma \mathrm{VA}=\mathrm{NVAP}+\mathrm{NVAPM}+\mathrm{NVAT}+\mathrm{NVAE}+\mathrm{NVAPE}
$$

The sum of operational benefits is:

$$
\Sigma \mathrm{OB}=\mathrm{OBP}+\mathrm{OBPM}+\mathrm{OBT}+\mathrm{OBE}+\mathrm{OBPE}
$$

According to the data for 2007/08-production year, Ethiopia is the first largest coffee producer in Africa and ranks fifth in the world next to Brazil, Viet Nam, Colombia, and Indonesia (see table 2.1 below). It is estimated that more than 280,000 metric tons of coffee is produced in Ethiopia every year with an increasing trend. The coffee Arabica is largely produced in Ethiopia making it the first largest producer of coffee in Africa. However, production supply is seasonal and fluctuates due to the climatic variations and so does with prices. Some projections show that production is estimated to expand by 3.91 percent annually over the period 1990-2008, on average.

A markets emerging, many coffee-dependent developing countries such as Ethiopia are struggling with production and marketing of their coffee. In the early 2000s, a historic world market price slump hit millions of coffee farmers hard, especially smallholder producers in Africa and Latin America (Ponte, 2002) as cited in IAAE, 2012. 


\section{Figure 2.5 Ethiopian coffee value chain mapping}

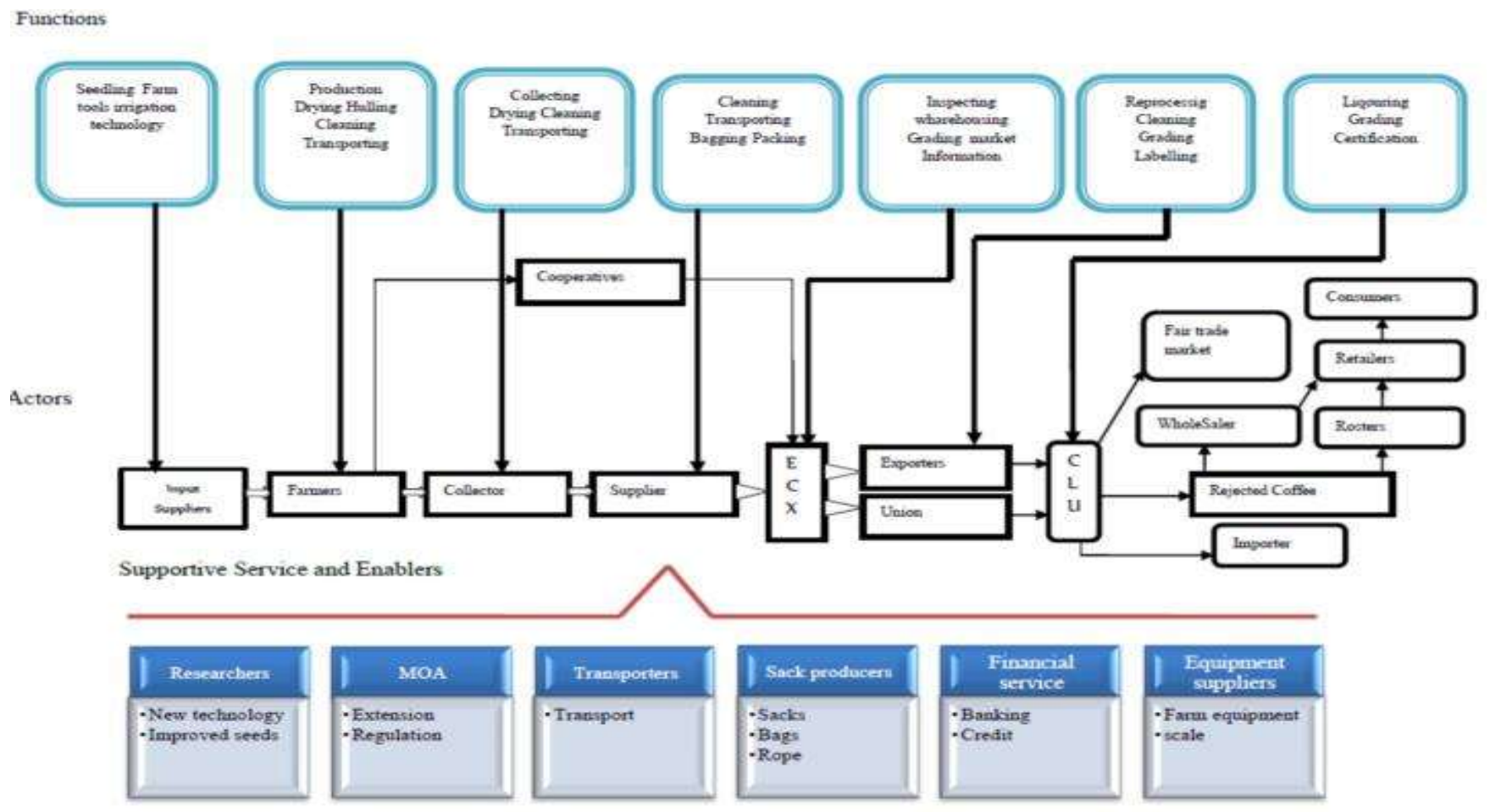

Source Jemal, 2013

\subsection{Challenges of Coffee Value Chain in Ethiopia}

\subsubsection{Coffee Price Volatility}

Global coffee production varies from year to year according to weather conditions, disease and other factors, resulting in a coffee market that is inherently unstable and characterized by wide fluctuations in price. This price volatility has significant consequences for those who depend on coffee for their livelihood, making it difficult for growers to predict their income for the coming season and budget for their household and farming needs. When prices are low, farmers have neither the incentive nor resources to invest in good maintenance of their farms by applying fertilizers and pesticides or replacing old trees. When prices fall below the costs of production, farmers struggle to put adequate food on the table and pay medical bills and school fees - a major reason for children taken out of school to contribute to the family income by working on the farm or in the informal sector. In recent years the price of Arabica has swing (moving back and forwards) from a 30-year low of 45 cents a pound in 2001 to a 34-year high of almost 309 cents in 2011. Similarly, Robusta crashed to 17 cents a pound in 2001 before climbing to 120 cents in 2011. Therefore the volatility of coffee markets in combination with poor production infrastructure and services have sunk the majority of coffee producers in developing countries in low-input-lowoutput cycles and structural poverty (Fair trade and Coffee May 2012 and ToraBäckman, 2009). 


\subsubsection{Problems Encountered in Coffee Supply}

\subsubsection{Problems Related with Quality}

As cited by (Policy Analysis and Economic Research Team, 2008), there are many factors that contribute to the quality of coffee. They are mainly handlings by producers (man) and nature (Coffee variety, soil characteristics, moisture and manure supplied etc.). Natural phenomenon include altitude, duration and severity of rainfall, type of soil, $\mathrm{PH}$, genetic origin, location of producing area, chemicals and pesticides, harvesting methods and timing, packing and so forth. Supervision of quality coffee begins with the coffee seedlings and ends when the coffee is shipped out to the international market.

However, the supply of Ethiopia coffee (both wet-processed and sun-dried) to local and international market faces some basic quality problems. This quality problem makes the Ethiopian coffee unable to adequately compete in the international coffee market and earn reasonable price. Most of these problems affect and are related with having desirable quality with the proper spatial, time and quality distribution. The major quality problems that have observed on Ethiopia coffee include problems related to:

* Handling during harvesting and storing,

* Processing and warehousing,

* Inability to take care of the coffee plantation properly,

* Inability to control the moisture content of the coffee,

* Mixing high quality coffee with low quality, or coffee of one origin with or coffee with relatively better quality usually; which is usually done by coffee collectors or assemblers and whole sellers?

All these problems exert a negative influence on quality of coffee and made it not to be competitive and earn desirable prices in both local and international markets. The main sources of these problems among others include:

\footnotetext{
$\checkmark$ Inadequate capacity and awareness of coffee producers and processors on quality due to lack of technical support for coffee producers and processors;

Lack of sufficient standard coffee processing machine in the major coffee producing areas due to lack of capacity and awareness, or sometimes improper installation of coffee processing machine,

$\checkmark$

Lack of proper place for coffee processing,

Inadequate inspection and supervision of responsible bodies in the assembling, processing or preparation of coffee during harvesting. This may be due to negligence or lack of sufficient awareness.

$\checkmark$

Lack of proper regulatory and controlling system on coffee harvesting, assembling, storing, transporting and processing activities;

$\sqrt{ }$

Lack of proper storage with adequate facilities.
} 


\subsubsection{Inadequate Supply Response due to Insufficient Prices}

Farmers get very low prices compared to final boarder prices of the produce in the local market. The greatest parts of the marketing margin go to the marketing middlemen. Similarly, in international market, coffee export is not getting the proper price it deserves. This has become disincentive to farmers in their coffee production. Several studies show that many farmers has shifted from coffee production to other high value cash crops such as chat in the years where there were very low prices such that in the early first have of 2000s (like 2001). For this reason, the overall coffee supply has not also grown as significantly as it is required to be. This is termed as low supply response from the side of coffee producers.

\subsubsection{Problems Related With Information and Promotion}

Even though it is of high quality, Ethiopian coffee is the least advertised or promoted in the world market. Evidences show that roasters know that Ethiopian coffee is superior, but they cannot sell it because we have not approached. That is, one of the problems of coffee marketing in Ethiopia is that there is inadequate effort to promote coffee and ensure the rights for trade marks for the best and world-wide known Ethiopian coffee verities most of which are motive and number one in the world. Moreover, exporters have inadequate experience and coffee market information. So do farmers.

\subsubsection{Challenges to the coffee sector in Ethiopia}

According to (Ethiopian coffee export conference, 2012) Structural challenges, policy environment and sustainability are some challenges of coffee production and marketing in Ethiopia.

1. Structural challenges:

- Lack of competitiveness (low yields \& productivity);

- Poor access to market \& long supply chain;

- Lack of infrastructure;

- inadequate access to services (particularly financial, services, risk management etc.);

- Low value addition; and

biodiversityetc.)

- Inadequate technology transfer \& research (coffee genome, conservation,

2 Policy environment:

- Low levels of public investment in agriculture;

- Disengagement of the state in production \& marketing activities;

- Liberalization/agricultural reforms historically poorly executed)

- Weak institutional framework in many countries

3. Sustainability:

( Low adaptation and mitigation to climate change (and other adverse weather events)

( Minimum Conservation of biodiversity

( Little Social sustainability: empower women and attract youth

( Competition for land (subsistence farming, biofuels)

\subsubsection{Opportunities of coffee sector in Ethiopia}

Ethiopian coffee sector has bright prospects (Ethiopian coffee export conference, 2012): The country has suitable altitude, ample rainfall, optimum temperatures, appropriate planting materials, 
low labor costs and fertile soil. The country can sustainably produce and supply fine specialty coffee, with potential of producing all coffee types of the various world coffee growing origins(ICC 4, 2013).

\section{Grounds for optimism:}

-Strong potential to increase supply capacity/yields (transfer of technology)

-Promote value addition

-Differentiation through brand awareness (e.g. Yirgacheffe, Sidamo etc.

- Importance of traceability

\section{Create an enabling policy environment:}

- Support agricultural research and development

-Improve access to price risk management tools

-Sustainable development

-promote a strong institutional framework to better coordinate policy

-Macroeconomic policy

\section{Stimulate local consumption:}

Ethiopia is not only the birthplace, an important producer, and a leading exporter of Arabica coffee, but also a heavy consumer. Ethiopians are the highest coffee consumers in Africa. Coffee is strongly ingrained in Ethiopian culture ("coffee ceremony")

\subsection{CONCLUSION AND RECOMMENDATION}

\subsection{Conclusion}

Ethiopia has a good potential to catch-up the high value coffee market in the world since buyers increasingly appreciate it as high quality coffee. However, Ethiopia is not benefited from this product because of two reasons: quality deteriorates along the value chain and the value addition is almost negligible. Practically, the majority of coffee is exported in the form of green beans to be roasted outside Ethiopia. Due to this reason, the profit plow back to Ethiopian poor farmers from the end users is less than $10 \%$. It is this small amount that covers about $65 \%$ of the nations export.

As a result, in spite of the comparative advantage in flavor, the Ethiopian green coffee price in the international market is lower than other countries' price. In addition, actors are not fairly priced because of quality and value addition. The causes for poor quality are mainly associated with harvesting and post-harvesting practice including collection, dry and wet processing, storage and transportation.

\subsection{Recommendations}

- In the future, research should be undertaken upon the significance of government strategy that enforces a firm to participate in one stage of the value chain for quality improvement and value addition.

- The value chain actors must play a critical role to increases the profit plow back in the Ethiopian coffee sector and then will significantly improve living standards of the poor who are at the source of the chain.

- The actors in the value chain, government, and non-government organizations should divert their efforts toward reducing deteriorating and value addition. 
- Policy and strategy which includes smallholder producers in coffee value chain and value addition (win-win strategy) must be designed

- Good extension services, farmer school, improved coffee variety, expert, credit and finance service must be provided for coffee producer farmer in order to increase coffee value addition and reduce coffee post harvest loss through providing infrastructure such as , communication, road, market access ability and etc.

\section{REFERENCES}

Alemseged Assfa, GetanehArega, 2013. Ethiopian Coffee Exporters Association ECEA:Analysis of Coffee Supply, Production, Utilization and Marketing Issues and Challenges in Ethiopia. Policy Analysis and Economic Research Team July, 2008Addis Ababa

Berhanu etal, 2013.Quality and Value Chain Analysis of Ethiopian Coffee. Journal of Agriculture and Social Research, 13(2), 2013

CSA. 2007. Annual Statistical Abstract. Addis Ababa Ethiopia.

Dempsey, J., 2006. A Case Study of Institution Building and Value Chain Strengthening to Link Ethiopian Cooperative Coffee Producers to International Markets, Addis Ababa, Ethiopia.

Ethiopian Coffee Export Conference (8 - 9) November 2012 Addis Ababa Ethiopia (www.ico.org)

Gemechu, F and Struthers, J (2007). Coffee Price Volatility in Ethiopia: Effects of Market Reform Programmes. Published online 4 May 2007 in Wiley Inter Science, Journal of International Development, 19, 1131-1142. UK.

John etal, 2010. An enterprise map of Ethiopia. International Growth Centre, London, UK. ISBN 9781907994005.

Kufa, T. 2012. Recent coffee research development in Ethiopia, Presentation at the "Ethiopian Coffee Export Conference: Strengthening the Legacy of Our Coffee”, November 8-9, 2012, Hilton, Addis Ababa

Nure, D. 2008. Mapping quality profiles of Ethiopian coffee by origin, in Eds. Adugna, G., Bellachew, B., Shimber, T., Taye, E., Kufa, T. 2008. Coffee diversity \& knowledge, Ethiopian Institute of Agricultural Research, Addis Ababa, Ethiopia: 317- 227

Petit, N. (2007) 'Ethiopia's Coffee Sector: A Bitter Or Better Future?',Journal of Agrarian Change $7(2): 225$

Tefera, A., and T. Tefera. 2013. Ethiopia: Coffee Annual Report, Gain report ET-1302, USDA

ToraBäckman 2009. Fair-trade coffee and development a field study in Ethiopia national konomiska institutional vidlunds university Department of Economics at the University of Lund Minor Field Study Series No. 188, S-220 07 Sweden.

ToraBäckman, 2012. Fair-trade coffee and development a field study in Ethiopia Selected Paper prepared for presentation at the Triennial Conference, Fozdo Iguaçu, Brazil, 18 -24 International association of agricultural economists (IAAE).

USDA as cited by index mundi, 2008Worako, T., Van Schalkwyk, H., Alemu, Z., and Ayele, G., 2008. Producer Price and Price Transmission in a Deregulated Ethiopian Coffee Market, Journal of Agrekon, Vol 47, No 4. 
Minten, Bart; Dereje, Mekdim; Engeda, Ermias; Kuma, Tadesse. 2015. Coffee value chains on the move: Evidence from smallholder coffee farmers in Ethiopia. ESSP II Working Paper 76.

Washington Ethiopia: Ethiopian Development Research Institute (EDRI). , D.C. and Addis Ababa, International Food Policy Research Institute (IFPRI). 